\section{THU0652 COMPARATIVE COST PER RESPONSE FOR FOUR CLINICAL OUTCOMES OF TOCILIZUMAB MONOTHERAPY VERSUS ADALIMUMAB MONOTHERAPY IN A HEAD-TO-HEAD RANDOMISED DOUBLE-BLIND SUPERIORITY TRIAL (ADACTA) IN PATIENTS WITH RHEUMATOID ARTHRITIS}

J. Best, J. Pei. Genentech, Inc., South San Francisco, USA

Background: The cost-effectiveness of different biologic therapies is an important component in guiding treatment decisions for patients with rheumatoid arthritis (RA).

Objectives: To compare drug and adverse event costs and cost per successful clinical response with tocilizumab (TCZ) monotherapy vs adalimumab (ADA) monotherapy in patients with RA.

Methods: Patients in the ADACTA trial ${ }^{1}$ were randomised to either TCZ $8 \mathrm{mg} / \mathrm{kg}$ intravenously every 4 weeks or ADA $40 \mathrm{mg}$ subcutaneously every 2 weeks as monotherapy for 24 weeks. Drug costs of $\$ 397.71 / 80 \mathrm{mg}$ vial for TCZ (plus $\$ 136$ administration cost per infusion) and $\$ 2220.62 / 40 \mathrm{mg}$ for ADA were based on Wholesale Acquisition Costs (WAC) drug prices (July 2017). Outcomes included patient-level drug costs and cost of hospitalisation due to adverse events, and cost per response. Cost per response was calculated by dividing the mean drug plus administration cost by the proportion of patients achieving Disease Activity Score-28 joints (DAS28) $<2.6$ (remission) or American College of Rheumatology response criteria $20 \% / 50 \% / 70 \%$ (ACR20/ACR50/ACR70). The proportions of patients achieving DAS28 $<2.6$, ACR 20, ACR50 and ACR70 were $39.9 \%, 65.0 \%$, $47.2 \%$ and $32.5 \%$ for $T C Z$, respectively, and $10.5 \%, 49.4 \%, 27.8 \%$ and $17.9 \%$ for ADA, respectively; $p<0.0001, p=0.0038, p=0.0002, p=0.0023$ for TCZ vs ADA, respectively. Hospitalisation costs were calculated using the daily hospital cost of $\$ 2433$ (2017) and number of hospital days.

Results: Among the 163 patients treated with TCZ and 162 with ADA, mean total drug and administration costs per patient over 24 weeks were $\$ 16,674.74$ and $\$ 23,357.63$, respectively. Mean drug and administration costs were lower per each clinical response achieved with TCZ compared with ADA (DAS28 <2.6: $\$ 41791$ vs $\$ 222,454$; ACR20: $\$ 25653$ vs $\$ 47,283$; ACR50: $\$ 35328$ vs $\$ 84,020$; ACR70: $\$ 51307$ vs $\$ 130,490)$. The total hospital days/costs were $32 / \$ 77856$ for TCZ and 43/\$1 04619 for ADA.

Conclusions: In this comprehensive comparative assessment, the cost to achieve all four clinical responses was lower for patients receiving TCZ than for ADA.

\section{REFERENCE:}

[1] Gabay C, et al. Lancet 2013;381:1541-1550.

Acknowledgements: This study was funded by Genentech, Inc

Disclosure of Interest: J. Best Shareholder of: Genentech, Inc., Employee of: Genentech, Inc., J. Pei Shareholder of: Genentech, Inc., Employee of: Genentech, Inc.

DOI: 10.1136/annrheumdis-2018-eular.2009

\section{THU0653 CHANGES IN RHEUMATOLOGY PROVISION AND PRACTICE IN A PUBLICLY-FUNDED SINGLE PAYER HEALTHCARE SYSTEM}

J. Widdifield ${ }^{1}$, S. Bernatsky ${ }^{2}$, V. Ahluwalia ${ }^{3}$, C. Barber ${ }^{4}$, L. Eder ${ }^{5}$, C. Hofstetter ${ }^{6}$,

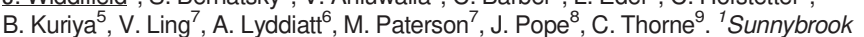
Research Institute, Toronto; ${ }^{2}$ Mc Gill University, Montreal; ${ }^{3}$ William Osler Health System, Brampton; ${ }^{4}$ University of Calgary, Calgary; ${ }^{5}$ University of Toronto; ${ }^{6}$ Ontario Rheumatology Association; ' Institute for Clinical Evaluative Sciences, Toronto; ${ }^{8}$ Western University, London; ${ }^{9}$ Southlake Regional Health Centre, Newmarket, Canada

Background: The global shortage of rheumatologists is an increasing concern. Statistics from physician surveys have projected changes in the workforce composition (ageing, feminization, and generational trends), which have implications for the workforce clinical activity. In order to adequately document the issues and potential solutions, more detailed information is needed regarding clinical activity, demographic changes and the implications of these, in a population-based sample.

Objectives: To describe changes in the number, demographics and clinical activity of Ontario rheumatologists over the past decade.

Methods: We analysed administrative health data from 2000 to 2013 in Ontario, Canada, where all 13 million residents are covered by a publicly funded healthcare system. Rheumatologists, and their characteristics, were identified using a validated physician registry. We used fee-for-service billing claims to quantify clinical activity levels expressed as full-time equivalents (FTE). Physicians below the 40th percentile of total billings were classified as providing less clinical activity
( $<1$ FTE i.e. professor/scientist); 40-60th percentile were classified as 1 FTE; and $>60$ th percentile as $>1 \mathrm{FTE}$ (i.e. high volume community practice).

Results: In 2000, there were 146 rheumatologists in Ontario (88 of whom worked $\geq 1$ FTEs); this increased to 187 rheumatologists (114 $>1$ FTEs) in 2013 Despite the increase, due to an increase in the Ontario population over this time, the proportion of Ontarians seen by a rheumatologist annually remained constant $(2.7 \%)$ as was the overall provincial per capita supply (1.2 rheumatologists per 75000 population, $0.7 \mathrm{FTEs} / 75,000)$. In $2000,34 \%$ of rheumatologists were female compared to $48 \%$ in 2013. During this time, the proportion of rheumatologists aged $>60+$ years increased $(16 \%$ to $26 \%$ ). The annual median (IQR) number of days of clinical service decreased from $220^{178-243}$ days in 2000 to $176^{138-}$ ${ }^{213}$ days in 2013. The percentage of rheumatologists with patient encounters on at least 209 days/year (an alternative FTE benchmark) showed a downward trend from $46 \%$ in 2000 to $22 \%$ in 2013. Male rheumatologists had more patient encounters each year, and a higher proportion of male rheumatologists worked as $\geq 1$ FTE. Average practice sizes declined over time (figure 1A), as did the median number of patient encounters per rheumatologist per year (figure 1B).

A

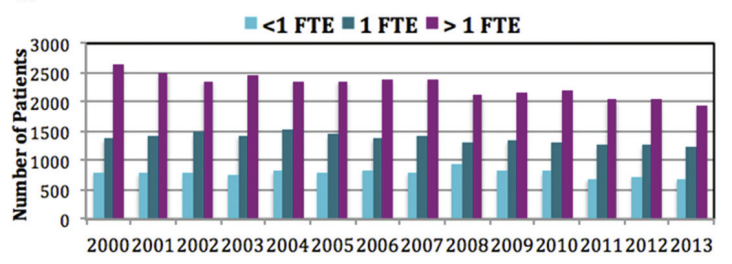

B

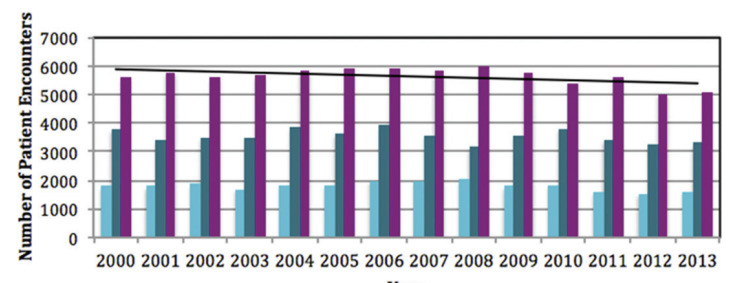

Year

Abstract THU0653 - Figure 1. A) Average Rheumatology Practice/Panel Size (Number of Unique Patients per Rheumatologists) According to FTE Classification; B) Average Number of Patient Enounters per Rheumatologist According to FTE Classification

Conclusions: Although there has been an increase in the number of rheumatologists, the per capita supply and access to rheumatologists have remained unchanged. We observed changing workforce demographics and declining clinical activity over time. Factors affecting clinical activity (including an ageing and greater feminization of the workforce, clinic saturation, increasing care complexity, models of care, greater demands for continuing medical education and research activity) warrants further study.

Disclosure of Interest: None declared

DOI: 10.1136/annrheumdis-2018-eular.3372

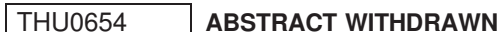

\section{THU0655 PATIENTS' EVALUATION OF DUTCH HEALTH CARE IN SYSTEMIC SCLEROSIS: UNMET NEEDS AND PREFERENCES}

J. Spierings ${ }^{1}$, C.H. van den Ende ${ }^{2,3}$, M.R. Schriemer ${ }^{4}$, J.K. de Vries-Bouwstra ${ }^{5}$, M. C. Vonk ${ }^{3} .{ }^{1}$ Department of Rheumatology and Clinical Immunology, University Medical Centre Utrecht, Utrecht, ${ }^{2}$ Department of Rheumatology, st Maartenskliniek; ${ }^{3}$ Department of Rheumatology, Radboud University Medical Centre, Nijmegen; ${ }^{4}$ Schriemer Peilt, Rotterdam; ${ }^{5}$ Department of Rheumatology, Leiden University Medical Centre, Leiden, Netherlands

Background: Systemic sclerosis (SSc) is a chronic, heterogeneous autoimmune disease with a large impact on quality of life. To optimise health care, more insight is needed in patients' experiences of the currently provided care.

Objectives: To identify unmet needs and preferences from a patient point of view regarding health care in the Netherlands

Methods: 2093 patients with SSc, from both regional $(n=7)$ and university hospitals $(n=6)$ in the Netherlands, were invited through their rheumatologist for an online, anonymous questionnaire comprising multiple choice, multiple response 